\title{
AJUSTE FISCAL NOS ESTADOS: UMA ANÁLISE DO PERÍODO 1998-2006*
}

\author{
Sérgio Wulff Gobetti ${ }^{* *}$
}

\begin{abstract}
RESUMO O objetivo deste artigo é analisar a forma de enquadramento dos estados ao Programa de Ajuste Fiscal (PAF) e à Lei de Responsabilidade Fiscal (LRF), destacando seus impactos nas escolhas de alocação dos recursos públicos e na taxa de investimento. Os resultados obtidos após minucioso trabalho de depuração das bases de dados confirmam a melhoria da situação financeira de estados no período posterior à LRF, mas sugerem que existe um trade-off entre os indicadores fiscais, de um lado, e os investimentos e gastos em infraestrutura, de outro, exigindo uma reflexão sobre a qualidade e sustentabilidade do ajuste fiscal. Os dados orçamentários analisados também apontam evidências de contabilidade criativa.
\end{abstract}

Palavras-chave: regras fiscais; ajuste fiscal; investimentos públicos; contabilidade criativa

Código JEL: E62; H71; H72

\section{FISCAL ADJUSTMENT IN BRAZILIAN STATES:}

\section{AN ANALYSIS OF PERIOD 1998-2006}

\begin{abstract}
The objective of this article is to offer an analysis of the accommodation by Brazilian states with Fiscal Adjustment Program and with Fiscal Responsibility Act (FRA), showing their impacts on the choices of public resources allocation and on the investment rate. The results obtained after detailed work of data depuration confirm the improvement of financial situation of the states in the period post FRA, but also suggest the existence of a trade-off between fiscal indicators and infrastructure investment, demanding a reflection about the quality and the sustainability of the fiscal adjustment. The budget data analyzed also indicate evidences of creative accountability.
\end{abstract}

Key words: fiscal rules; fiscal adjustment; public investments; creative accountability

* Artigo recebido em 22 de maio de 2009 e aprovado em 27 de novembro de 2009.

** Mestre e doutor em Economia pela UNB, técnico de Planejamento e Pesquisa do Instituto de Pesquisa Econômica Aplicada - DF, e-mail: swgobetti@gmail 


\section{INTRODUÇÃO}

Os estudos teóricos e empíricos mais recentes que avaliam a eficácia da Lei de Responsabilidade Fiscal (LRF), tais como Giuberti (2006), Menezes (2006) e Souza (2007), têm explorado principalmente a relação de variáveis institucionais e político-eleitorais com o equilíbrio fiscal de estados e municípios no Brasil, mas dedicam pouca ou nenhuma atenção a outros aspectos relevantes reportados na literatura internacional sobre regras fiscais, tais como o trade-off envolvido na perseguição de metas de equilíbrio orçamentário e a tendência à utilização de procedimentos de "contabilidade criativa" na ausência de suficiente transparência orçamentária e de órgãos independentes de fiscalização.

O objetivo deste artigo é preencher essa lacuna, verificando de que forma os resultados fiscais de estados estão evoluindo. Em particular, buscamos investigar se os superavits primários não têm sido elevados às custas de redução de investimentos e se a relativa contenção das despesas de pessoal — um dos objetivos implícitos da LRF — não está sendo alcançada pela expansão de outras despesas de correntes associadas a serviços de terceiros.

A preocupação com tais aspectos se justifica pela forma como a LRF foi implementada no Brasil. Embora a lei tenha sido formulada com base em princípios como o planejamento e a transparência orçamentária, o que realmente motivou o governo federal a tentar aprová-la foi a necessidade de integrar estados e grandes municípios no programa de ajuste fiscal negociado com o Fundo Monetário Internacional (FMI), no final de 1998.

Um primeiro passo nessa direção havia sido dado ainda em 1997, com a Lei no 9.496/1997, que estabeleceu critérios para a consolidação e o refinanciamento das dívidas de 25 estados pela União. Nos contratos que assinaram com a União, os estados comprometeram-se a seguir um rígido programa de reestruturação e ajuste fiscal, que previa, entre outras medidas, a destinação de um limite mínimo das suas receitas ao pagamento das prestações da dívida refinanciada. Na prática, isso acabava por induzir os governos estaduais a obterem, no agregado, um superavit primário que lhes permitisse cumprir os contratos.

Evidentemente, as regras fiscais forçaram os administradores a se comprometer com um padrão mínimo de disciplina fiscal, mas também levaram, na prática, à busca de saídas criativas no nível da contabilidade orça- 
mentária para alcançar e atender aos limites da legislação, conforme tem sido largamente reportado na imprensa escrita. ${ }^{1}$

De acordo com Milesi-Ferretti (2000, p. 3), "a imposição de metas numéricas pode encorajar o uso de práticas duvidosas de contabilidade, reduzindo, consequentemente, o grau de transparência no orçamento governamental". Por isso, os teóricos das regras fiscais, como Inman (1996), defendem que haja mecanismos de transparência da contabilidade pública e que a fiscalização dos limites seja feita por um órgão independente, capaz de impor significativas penalidades aos infratores. No caso da LRF, essa transparência deveria ser garantida pela uniformização dos critérios de contabilidade e pela publicação, inclusive na Internet, dos relatórios de gestão fiscal e de execução orçamentária. Na prática, entretanto, nem uma condição nem outra têm sido plenamente atendidas.

Alguns Executivos estaduais - e a maioria dos Legislativos e Judiciários — não disponibilizam os relatórios ao público, e muitos dos que disponibilizam seguem critérios distintos das normas da Secretaria do Tesouro Nacional (STN). Como agravante, os Tribunais de Contas dos Estados (TCEs), responsáveis pela fiscalização, muitas vezes endossam ou adotam fórmulas de "contabilidade criativa". Nesse contexto de ausência de transparência, há grandes dificuldades em avaliar a real melhoria dos indicadores fiscais de estados e seus impactos sobre a qualidade de gestão, desafio que encaramos ao longo deste artigo.

\section{REGRAS FISCAIS: CONTEXTO PRÁTICO E PANORAMA TEÓRICO}

As regras fiscais, de orçamento equilibrado ou de limitação das despesas e da dívida, como as previstas na LRF, popularizaram-se na década de 1990 a partir de uma série de reformas adotadas pelos países da OCDE e em desenvolvimento com o objetivo de conter o crescimento do deficit público. Nos Estados Unidos, a primeira tentativa nesse sentido foi adotada nos anos 1980, com a lei Gramm-Rudman-Hollings (GRH), que não conseguiu alcançar sua meta de orçamento equilibrado e foi substituída em 1990 pelo Budget Enforcment Act (BEA), mais bem-sucedido ao controlar gastos e receitas.

Na União Europeia, o Tratado de Maastricht previu um pacto pela estabilidade que, desde 1997, obriga os países-membros a manterem o deficit 
nominal e a dívida pública sob limites preestabelecidos (3 e 60\% do PIB, respectivamente). Já a Nova Zelândia, em 1994, aprovou seu Fiscal Responsability Act, baseado principalmente no princípio da transparência e em compromissos, e não metas, de redução do endividamento e de estabilização das alíquotas tributárias. Essas três experiências, principalmente a neozelandesa, tiveram importante influência na elaboração da LRF brasileira.

Apesar das diferenças de enfoque, os proponentes de regras fiscais em geral reivindicam a relevância "normativa" do trabalho seminal de Barro (1979) e Lucas e Stokey (1983) sobre o ciclo econômico e o equilíbrio intertemporal do orçamento de governo, mas desenvolvem uma teoria "positiva" baseada na necessidade de impor limites e restrições institucionais para neutralizar um suposto viés gastador dos governantes. Ou seja, enquanto a teoria neoclássica normativa admite um papel de estabilizador automático do deficit durante as fases recessivas do ciclo econômico, a economia política positiva apregoa a busca do equilíbrio orçamentário em todos os anos, e não apenas a médio e longo prazos.

Essa necessidade existiria, segundo os defensores das regras fiscais, porque os deficits públicos estariam se perpetuando em diversos países mesmo nos momentos de paz e prosperidade, quando, pela lógica da teoria dos ciclos econômicos, deveria haver superavits. Como a teoria neoclássica, ao contrário de abordagens heterodoxas, não consegue identificar razões econômicas para esse fenômeno, um caminho natural foi buscar explicações exógenas ao sistema econômico. ${ }^{2}$

A abordagem político-institucional da escola de public choice, sintetizada no trabalho de Buchanan e Wagner (1977), tenta explicar os deficits públicos persistentes a partir da hipótese de que os cidadãos sofrem de "ilusão fiscal" por não compreenderem a restrição orçamentária do governo. Ou seja, os eleitores superestimariam os benefícios correntes dos gastos e subestimariam o custo futuro de aumentos na tributação; e os políticos oportunistas extrairiam vantagem dessa confusão para aumentar os gastos e tentar se reeleger.

A razão para esse comportamento irracional, de acordo com a teoria neoclássica, seria a existência de informações limitadas à disposição dos cidadãos, o que estimularia os políticos a sinalizar competência procurando fornecer o máximo de bens públicos com o mínimo de imposto, segundo Cukierman e Meltzer (1986) e Rogoff (1990). Esse fenômeno de assimetria de informações 
seria tanto maior quanto menos transparentes fossem o sistema de contabilidade e o orçamento públicos. A essas hipóteses, Alesina e Tabellini (1990) acrescentam outras de natureza político-institucional para entender por que os deficits cresceram nos anos 1980 e 1990. Entre elas, a suposição de que haveria uma maior polarização política e alternância de poder nessas décadas, e que isso teria estimulado os governantes a aumentar o endividamento para tentar inviabilizar a administração dos sucessores adversários.

Por outro lado, Alesina e Perotti (1996) admitem que leis baseadas no equilíbrio orçamentário podem não ser ótimas no sentido de Pareto, seja por impedirem políticas anticíclicas do tipo keynesianas, seja por induzirem distorções de acordo com o princípio de tax smoothing, segundo o qual a melhor política é manter a taxa de tributação constante em face de oscilações temporárias de gastos. No contexto de um viés deficitário, entretanto, os autores argumentam que esse tipo de lei seria a "segunda melhor solução", justificando-se a imposição de limites mais rígidos para os gastos e para o endividamento.

Todas essas interpretações de cunho neoclássico evidentemente influenciaram não só a elaboração da LRF brasileira e a adoção de metas fiscais, como também têm influenciado outros aspectos da política fiscal e do processo orçamentário do país. Uma consequência indesejável das restrições à política fiscal no Brasil, entretanto, tem sido a redução da taxa de investimento público, que caiu da ordem de 4\% do PIB na década de 1970 para menos de $2 \%$ nos anos recentes, de acordo com as séries de dados do IBGE e do Ipeadata.

Poterba (1996) reconhece, por exemplo, que, no contexto de regras fiscais, se o processo orçamentário é "míope" e atribui excessivo peso ao custo corrente de um projeto, independentemente de seus benefícios futuros, então os investimentos de longo prazo podem enfrentar mais dificuldades políticas para serem aprovados do que projetos de curto prazo. Essa possibilidade tem sido levantada em favor da adoção de um orçamento de capital separado do orçamento corrente.

Alesina e Bayoumi (1996) admitem a relevância de alguns questionamentos críticos sobre a adoção de regras de orçamento equilibrado. Primeiro, sobre a eficácia de tais regras incentivarem a disciplina fiscal ou, em vez disso, encorajarem procedimentos de "contabilidade criativa". Segundo, pe- 
los custos dessas regras em termos de perda de flexibilidade na política fiscal, tanto no paradigma neoclássico de tax smoothing quanto no paradigma keynesiano de políticas anticíclicas.

Embora os autores encontrem evidências, para os Estados Unidos, de que a restrição macroeconômica imposta pela regra de orçamento equilibrado seria menos importante para os governos locais e estaduais do que para o nacional, o mesmo não pode ser dito sobre o trade-off envolvendo o

processo de ajuste fiscal. Como já foi mencionado, há uma tendência de a visão de curto prazo sobre os custos desestimular os investimentos em infraestrutura, o que afeta não só o bem-estar da localidade como o próprio equilíbrio macroeconômico.

Essas considerações de natureza teórica, do nosso ponto de vista, reforçam a necessidade de analisar os possíveis trade-offs e mudanças na composição dos gastos públicos decorrentes da imposição dessas regras, o que faremos para a esfera estadual.

\section{METODOLOGIA DE ANÁLISE: INDICADORES E BASE DE DADOS}

Os indicadores fiscais e orçamentários usados para avaliar a gestão dos estados foram calculados a partir dos dados disponibilizados anualmente pela Secretária do Tesouro Nacional (STN) por meio do arquivo "Execução Orçamentária dos Estados” (doravante EOE), que é constituído pelas informações orçamentárias e patrimoniais prestadas pelos próprios entes, em atendimento ao art. 51 da LRF, que atribui à STN o papel de consolidar as contas do setor público a partir de um plano contábil uniformizado.

Na seleção e definição dos indicadores fiscais, buscamos compatibilizar a disponibilidade concreta dos dados da EOE com os conceitos e parâmetros da Lei de Responsabilidade Fiscal. Algumas regras previstas na LRF podem ser facilmente traduzidas em metas numéricas, como os limites de gasto com pessoal e de endividamento, mas outras são meros princípios que sinalizam a busca de uma situação de maior equilíbrio nas finanças públicas, a curto e longo prazos. ${ }^{3}$

O art. 42 da LRF, por exemplo, que veda a assunção de despesas sem lastro financeiro nos últimos dois quadrimestres de um mandato, foi concebido com o objetivo de impedir que administradores públicos inviabilizassem 
a gestão do seu sucessor transferindo-lhe um volume de obrigações financeiras - como restos a pagar (RAP) - superior às disponibilidades de caixa. A efetividade desse dispositivo tem sido objeto de controvérsia no âmbito dos Tribunais de Contas, em virtude de lacunas na redação do texto da lei, ${ }^{4}$ mas isso não nos impede de adotar um critério para sua mensuração, o que é feito pela comparação das obrigações e disponibilidades financeiras, de acordo com as orientações da STN para preenchimento dos demonstrativos que compõem o Relatório de Gestão Fiscal (RGF) e o Relatório Resumido de Execução Orçamentária (RREO). ${ }^{5}$

A diferença entre as disponibilidades e obrigações financeiras constitui o que chamamos, a partir de agora, de suficiência de caixa. Quando positivo, expressa um excesso de disponibilidades sobre as obrigações; quando negativo, reflete uma insuficiência financeira para cobrir os restos a pagar e outras obrigações. Além de importante inibidor dos gastos ao final de mandato, tal parâmetro oferece uma forma alternativa de mensurar a evolução fiscal pelas variações no balanço patrimonial.

De certa forma, a suficiência de caixa pode ser relacionada a outro indicador fiscal incluído na nossa análise, o superavit primário. A diferença é que este é uma variável de fluxo apurado pelo conceito acima da linha, comparando receitas e despesas não financeiras, enquanto aquela reflete uma posição de estoque, cuja variação entre dois períodos se aproxima (mas não equivale) ao resultado nominal apurado abaixo da linha. As diferenças entre os dois conceitos - acima e abaixo da linha - serão tratadas com mais profundidade em outra seção, ao comparamos nossos resultados com os relatórios do Banco Central.

Por fim, além dos quatro indicadores mencionados - despesa líquida de pessoal (PES_LIQ), dívida consolidada líquida (DCL), suficiência de caixa (SUF_CXA) e superavit primário (SUP_PRI), que integram o componente fiscal do nosso índice -, acrescentamos à análise indicadores orçamentários (ou de gestão) que refletem a composição das despesas públicas e que integrarão o componente de qualidade de gestão. De forma sintética, o quadro 1 apresenta os principais indicadores (e respectivos componentes) que usaremos na nossa análise, cuja memória de cálculo está detalhada nos Anexos 1 e 2 .

O período compreendido pela análise, pelas características da EOE, será o dos anos de 1998 a 2006. Como o plano de contas adotado pela STN mu- 
Quadro 1

\begin{tabular}{ll}
\hline & Glossário dos indicadores \\
\hline Dívida Consolidada (DC) & $=($ OP_CRE $)+($ OUT_DC $)$ \\
\hline Deduções da Dívida (DC_DED) & $=$ Ativo Financeiro Disponível - RAP Processado \\
\hline Dívida Consolidada Líquida (DCL) & $=($ DC_TOT) - (DC_DED) se (DC_DED) $>0$ \\
\hline Disponibilidades Financeiras (ATI_DIS) & $=$ Ativo Financeiro Disponível \\
\hline Obrigações Financeiras (PAS_OBR) & $=$ Restos a Pagar + Depósitos + Outras Obrigações \\
\hline Suficiência de Caixa (SUF_CXA) & $=$ (ATI_DIS) - (PAS_OBR) \\
\hline Receita Primária (REC_PRI) & $=$ Receita total, excluindo receitas financeiras e Fundef \\
\hline Despesa Primária (DES_PRI) & $=$ Despesa total, excluindo as financeiras \\
\hline Superavit Primário (SUP_PRI) & $=$ (REC_PRI) - (DES_PRI) \\
\hline Despesa Bruta de PesSOal (PES_TOT) & $=$ Despesa com pessoal, inclusive aposentadorias da ODC \\
\hline Deduções de Pessoal (PES_DED) & $=$ Elementos deduzíveis pela LRF \\
\hline Pessoal Líquido (PES_LIQ) & $=$ (PES_TOT) - (PES_DED) \\
\hline Despesa de Custeio (ODC_TOT) & $=$ ODC, excluindo aposentadorias e pensões \\
\hline Custeio da Máquina (ODC_MAQ) & $=$ Diárias, passagens e material de consumo \\
\hline Custeio de Auxílios (ODC_AUX) & $=$ Verbas indenizatórias, como auxílio-alimentação \\
\hline Custeio de Terceiros (ODC_TER) & $=$ Serviços de terceiros, consultorias e locação de mão de obra \\
\hline Investimentos (INV) & $=$ Despesas de capital em investimentos \\
\hline Receita Corrente Líquida (RCL) & $=$ Receita corrente, excluindo retenções Fundef \\
\hline Fonte: Anexos 1 e 2. &
\end{tabular}

dou a partir de 2002, tivemos de adotar uma metodologia de compatibilização das fórmulas de cálculo dos indicadores, o que também está detalhado nos anexos.

Em termos gerais, o plano de contas utilizado até 2001 pelos estados para preenchimento dos seus balanços anuais baseava-se na Lei no 4.320/1964. A partir de 2002, com a exigência de consolidação das contas do setor público estabelecida na LRF, o preenchimento da EOE passou a ser ajustado às regras de contabilidade que a STN já adotava para a esfera federal. A principal diferença entre os dois planos de contas está na estrutura de classificação das despesas: enquanto o plano antigo dividia as despesas correntes, por exemplo, em dois grandes grupos (custeio e transferências), o plano atual as divide em três categorias econômicas - Pessoal e Encargos Sociais (PES), Juros e Encargos da Dívida (JED) e Outras Despesas Correntes (ODC).

Do ponto de vista econômico, é importante notar que a abordagem anterior guarda alguma semelhança com a estrutura das Contas Nacionais, pois as despesas de pessoal não eram tratadas em bloco, como na contabilidade atual da STN. O GND Pessoal e Encargos Sociais reúne atualmente to- 
dos os elementos de despesa relacionados aos servidores públicos, enquanto no velho plano de contas os gastos com servidores ativos eram tratados como custeio e as despesas com inativos, como transferências a pessoas. Outra diferença é que as chamadas despesas indenizatórias, como diárias e ajudas de custo, antes eram classificadas como "Demais Despesas de Pessoal" e hoje integram o grupo ODC.

Além desses problemas, existem outros de origem contábil que também exigem cuidados especiais ao compararmos dados de diferentes anos. A análise das despesas de alguns estados, por exemplo, revela um salto aparentemente inexplicado no GND Pessoal e uma queda no GND ODC entre os anos 2003 e 2004 ou 2004 e 2005. Uma análise mais atenta, entretanto, revelará que as variações se explicam por uma mudança na forma de classificação das despesas com "Aposentadorias e Reformas" e "Pensões" por orientação do Ministério da Previdência. Isso ocorreu nos entes que institucionalizaram contas separadas para os fundos de previdência dos servidores, em cujo caso a Previdência passou a orientar que a despesa com inativos passasse a ser classificada em ODC, embora continue entrando no cálculo da despesa de pessoal da LRF (critério igualmente utilizado neste artigo).

Outra mudança importante no novo plano de contas e que foi considerada no cálculo dos indicadores diz respeito aos efeitos do Fundef. Até 2001, a orientação da STN era para que os municípios e estados já declarassem suas receitas líquidas da retenção do Fundef, mas muitos entes não o faziam assim; a partir de 2002, entretanto, a recomendação passou a ser de que as receitas fossem declaradas em valor bruto e que, ao final, fossem destacadas em separado as deduções para o Fundef.

\section{EVOLUÇÃO FISCAL DOS ESTADOS: PRINCIPAIS RESULTADOS}

A evolução fiscal dos estados será analisada nesta seção a partir dos indicadores apresentados anteriormente, cuja memória de cálculo está detalhada nos anexos. A tabela 1 sintetiza os resultados obtidos, como proporção da RCL, das principais variáveis que, do nosso ponto de vista, refletem a trajetória fiscal dos estados entre 1998 e 2006. Como podemos verificar, o endividamento dos governos estaduais, seja bruto (DC) ou líquido (DCL), depois do repique de 2002 e 2003 provocado pelos efeitos da crise cambial sobre o IGP-DI (indexador dos contratos de refinanciamento com a União), 


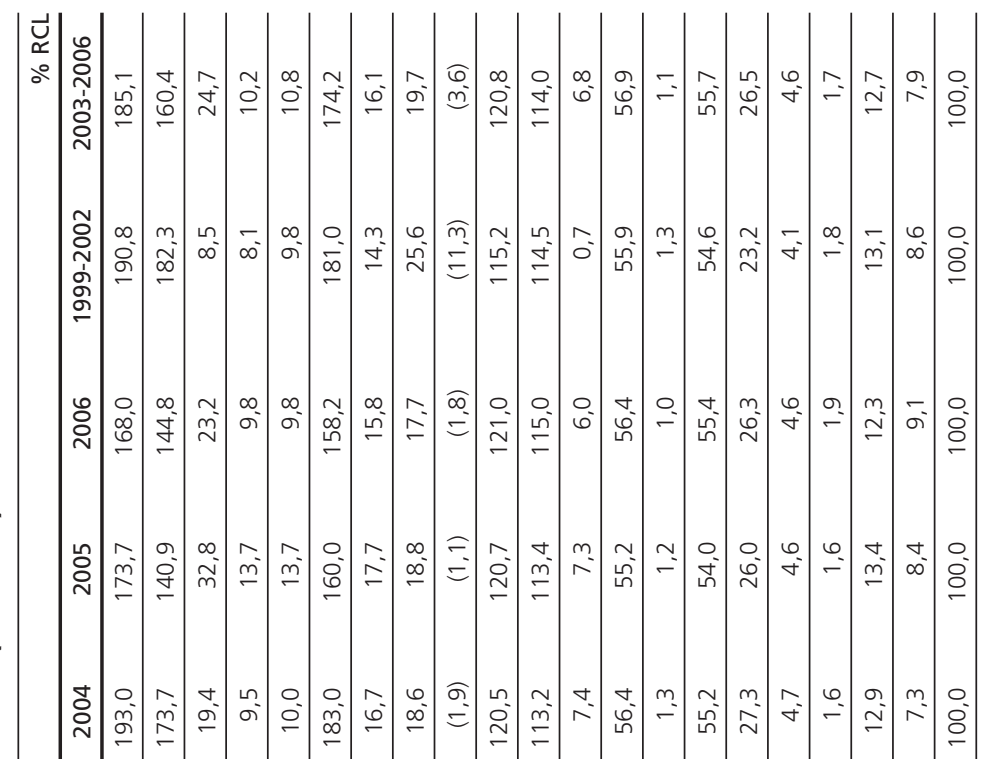

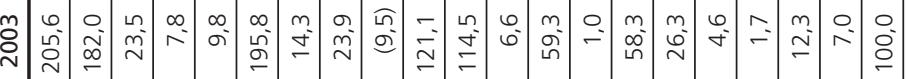

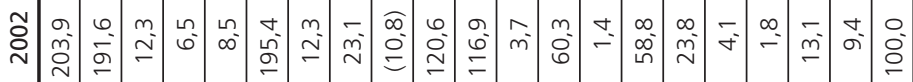

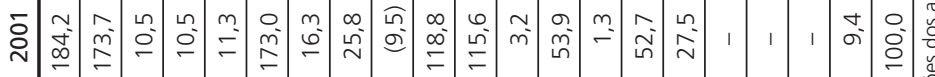

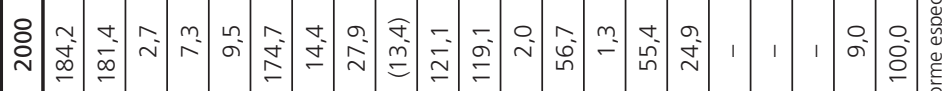

ริ

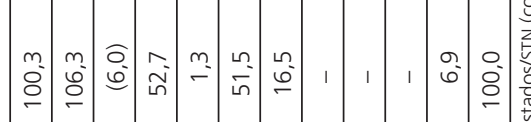

๙ั

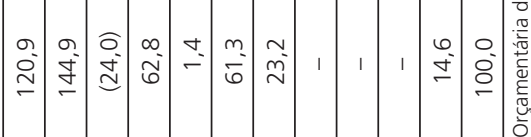

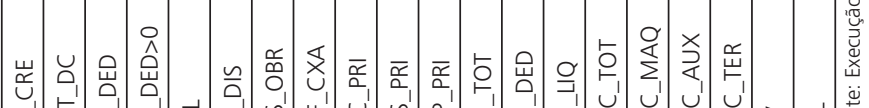

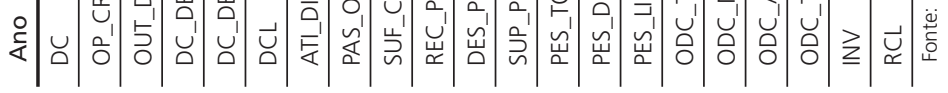


apresenta gradual redução. $\mathrm{O}$ mesmo pode ser dito em relação à suficiência de caixa (SUF_CXA), que reflete a diferença entre os principais componentes do ativo e passivo financeiro.

Por imposição da LRF, os governadores foram forçados, ao longo dos últimos quatros anos, principalmente, a reduzir a parcela das suas obrigações financeiras (com destaque para os restos a pagar) que não encontram cobertura nas disponibilidades de caixa. No total, a insuficiência de caixa em 2000 representava R \$ 15,5 bilhões ou 13,5\% da RCL dos estados; em 2006, esse valor baixou para R $\$ 4,4$ bilhões ou 1,84\% da RCL.

Em 2000, 17 estados apresentavam insuficiência de caixa; em 2006, esse número caiu para nove, e apenas três deles (AL, GO e RS) não conseguiram melhorar sua situação no período, ou seja, enfrentaram um agravamento da situação patrimonial e financeira, que, em alguns casos, também se reflete em um ritmo mais lento de redução do endividamento. ${ }^{6}$

Atualmente, pelos controles da STN, apenas dois estados (RS e AL) se encontram acima do limite de endividamento fixado pelo Senado em atendimento ao disposto na LRF, que é de duas vezes ou $200 \%$ o valor da RCL. No nosso trabalho, entretanto, como outras obrigações a pagar de longo prazo e todos os precatórios (e não apenas aqueles posteriores a 5/5/2000) foram incluídos no cálculo da dívida consolidada (por impossibilidade de discriminá-los), outros dois estados (SP e RJ) passam a registrar um endividamento líquido também superior a duas vezes a RCL. Por outro lado, entretanto, a RCL utilizada neste trabalho também é superior àquela publicada pelos estados, em decorrência dos motivos já expostos anteriormente, o que introduz um efeito de compensação no cálculo do indicador. A tabela 4 compara o indicador de endividamento líquido informado pelos estados à STN e aquele estimado neste trabalho de acordo com os balanços patrimoniais.

Os dados da tabela 1 mostram ainda que, no agregado, o resultado primário dos estados melhorou substancialmente desde a introdução da LRF, passando de valores negativos em 1998 e 1999 ou de um superavit de 2\% da RCL em 2000 para superavits de 6 a 7\% da RCL nos anos mais recentes. Essa melhoria do resultado primário decorre principalmente do crescimento da receita primária em relação à RCL, pois as despesas primárias, como se vê pela comparação das médias de 1999-2002 e 2003-2006, equivalentes a dois mandatos distintos de governador, estão absolutamente estabilizadas em torno de $114 \%$. 
Entre os principais componentes da despesa primária, destaca-se o crescimento da despesa de pessoal como proporção da RCL de 55,9\% da RCL entre 1999-2002 para 56,9\% entre 2003-2006. Ou seja, em pleno vigor da LRF, as despesas brutas (PES_TOT) e líquidas (PES_LIQ) com pessoal não caíram, apesar de os demonstrativos publicados pelos estados indicarem uma trajetória declinante para os gastos dos Executivos, o que será analisado com mais detalhes em outra seção deste capítulo. As despesas de custeio (ODC_TOT) chegaram a crescer de $23,2 \%$ para $26,5 \%$ da RCL entre os dois períodos, enquanto os investimentos caíram de uma média de 8,6\% para 7,9\% da RCL. Ou seja, as despesas de capital estão sendo relativamente comprimidas, enquanto as despesas correntes crescem.

A evolução das despesas e receitas é semelhante quando as comparamos com o PIB em vez da RCL. Isso porque a RCL tem se mantido mais ou menos estabilizada em torno de $10 \%$ do PIB, como vemos na tabela 2, mas as discrepâncias de alguns anos, como 1999, interferem nas médias. O superavit primário cresce de $0,1 \%$ para $0,7 \%$ do PIB na média dos dois mandatos analisados (1998-2002 e 2003-2006). A receita primária apresenta variação positiva de 0,4 ponto porcentual do PIB, e a despesa primária, redução de 0,3 ponto porcentual.

Analisando os anos individualmente, entretanto, percebemos que as receitas primárias estão crescendo há quatro anos ininterruptamente, depois de uma queda em 2003. O mesmo ocorre com as despesas, de modo que o resultado primário, nessa perspectiva, parece ter estagnado entre 0,6 e 0,7\% do PIB, embora em valores nominais e reais seja maior, visto que estamos em uma fase de crescimento da economia. Atualizando os valores pelo deflator do PIB, por exemplo, verificamos que as receitas primárias cresceram $27,0 \%$ em termos reais entre 2000 e 2006, enquanto as despesas primárias cresceram 22,6\%. O superavit primário resultante cresce $289,7 \%$ nesse período, indicando de forma incontestável, a melhoria desse indicador fiscal ao longo dos últimos seis anos, desde a instituição da LRF.

\subsection{O superavit primário e os problemas metodológicos}

A fim de investigar melhor o que está ocorrendo com o superavit primário dos estados, recorremos a uma comparação entre os valores deste trabalho 


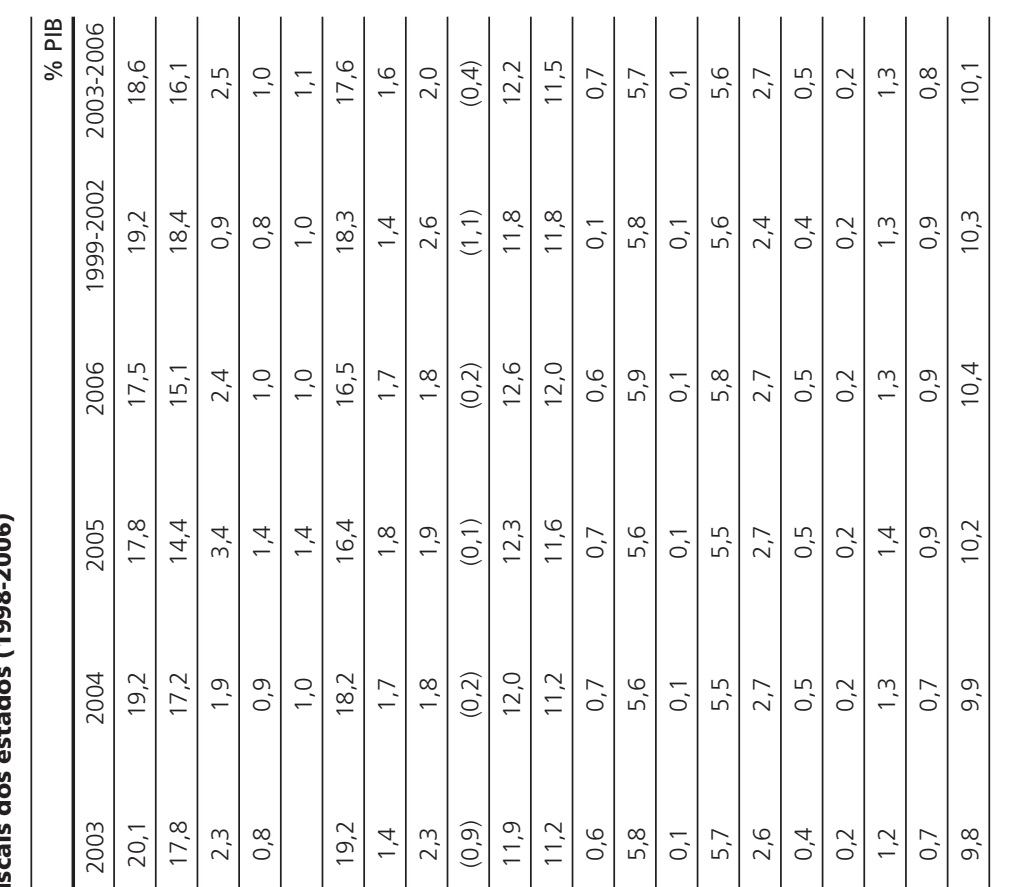

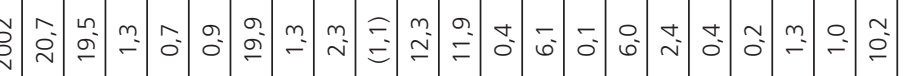

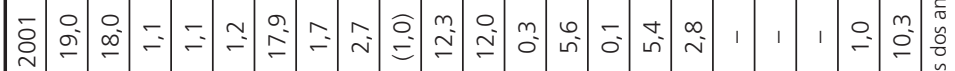

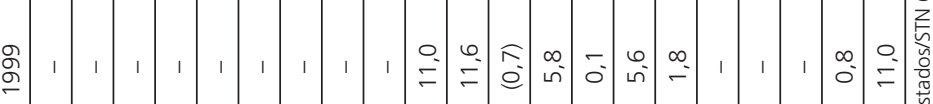

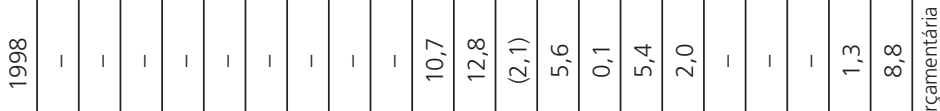

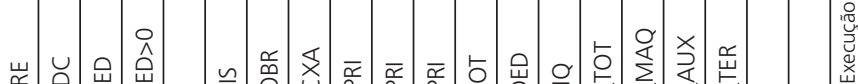

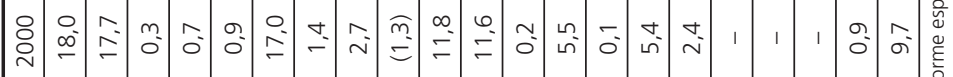

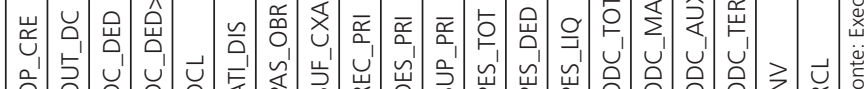

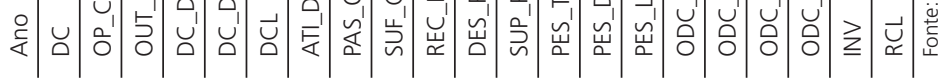


(SUP_PRI EOE), os informados pelos governos estaduais (SUP_PRI LRF) e os estimados pela STN e pelo Banco Central. Em primeiro lugar, é preciso esclarecer que existem duas diferenças básicas entre o nosso resultado, o informado pelos estados e pela STN, de um lado, e o do BC, de outro lado:

(1) As estimativas do BC seguem a metodologia "abaixo da linha" do Fundo Monetário Internacional (FMI), ou seja, que apura a necessidade de financiamento pela variação das dívidas do setor público entre dois pontos no tempo; a diferença entre os juros que incidem sobre essas dívidas e sua efetiva variação corresponde ao resultado primário.

(2) As estimativas que a STN e nós fizemos, assim como os valores informados pelos estados, seguem o critério “acima da linha”, assim chamado porque se baseia em uma comparação das receitas e despesas primárias, ou seja, que não tenham caráter financeiro.

(3) Além disso, as estimativas “acima da linha” mencionadas estão sendo calculadas a partir da execução orçamentária das despesas (competência), e não da sua execução financeira (caixa), como faz o Tesouro para o resultado primário do governo central; dessa forma, a mensuração da despesa pela ótica contábil, ou de competência, tende a criar um viés de superestimativa, como veremos.

(4) Esse último problema apontado - a diferença contábil-financeira - exige que analisemos a evolução dos restos a pagar para tentar verificar se, pelo menos no fluxo, as despesas empenhadas se igualam às despesas pagas.

(5) Por fim, existem diferenças entre os nossos valores e os da STN que se explicam pelo fato de estarmos considerando como despesas financeiras e não primárias as inversões financeiras voltadas à aquisição de títulos representativos de capital já integralizado e a concessão de empréstimos ou financiamentos; o próprio Tesouro classifica tais despesas como financeiras em seus manuais, mas preferiu não considerá-las nos cálculos por falta de informações sobre elas antes de 2002.

Depois desses esclarecimentos, vamos apresentar os dados na tabela 3, que sintetiza as diferenças entre as fontes e metodologias mencionadas e, ao mesmo tempo, é uma tentativa de compatibilizar uma comparação com os 
Tabela 3: Diferenças metodológicas na apuração do resultado primário dos estados

\begin{tabular}{|c|c|c|c|c|c|c|c|c|}
\hline & & & & & & & & R\$ milhões \\
\hline Ano & 2000 & 2001 & 2002 & 2003 & 2004 & 2005 & 2006 & $\sum 2000-06$ \\
\hline SUP_PRI LRF & 6.408 & 8.094 & 8.709 & 16.440 & 17.344 & 20.155 & 15.881 & 93.031 \\
\hline SUP_PRI STN & 2.260 & 4.137 & 4.557 & 10.174 & 13.342 & 14.422 & 13.296 & 62.188 \\
\hline SUP_PRI EOE & 2.262 & 4.317 & 5.605 & 10.999 & 14.215 & 15.995 & 14.626 & 68.020 \\
\hline \multicolumn{9}{|l|}{ Ajuste Caixa/ } \\
\hline Competência & 1.000 & 1.224 & 33 & 3.907 & 1.354 & 2.902 & $(1.561)$ & 8.860 \\
\hline \multicolumn{9}{|l|}{ SUP_PRI Est. } \\
\hline Acima Linha & 3.262 & 5.541 & 5.638 & 14.907 & 15.569 & 18.897 & 13.064 & 76.880 \\
\hline \multicolumn{9}{|l|}{ SUP_PRI BC } \\
\hline Abaixo Linha & 4.579 & 7.212 & 8.560 & 11.916 & 16.060 & 17.194 & 16.370 & 81.890 \\
\hline \multicolumn{9}{|l|}{ Diferença } \\
\hline \multicolumn{2}{|c|}{ (Acima-Abaixo) (1.317) } & $(1.670)$ & $(2.921)$ & 2.991 & (491) & 1.703 & (3.306) & $(5.010)$ \\
\hline
\end{tabular}

Fonte: Elaboração própria, consultando os dados publicados pela STN e pelo BC.

resultados do $\mathrm{BC}$ por meio de uma estimativa do ajuste de caixa/competência. Chama a atenção, em primeiro lugar, que o superavit primário informado pelos estados é bem superior a todas as demais fontes, inclusive o Banco Central, apesar de o estoque de restos a pagar ter crescido em todos os anos analisados, exceto 2006; ou seja, o fluxo de pagamentos está defasado em relação aos empenhos.

Comparando com os números estimados com base na mesma metodologia pela STN e por nós, por exemplo, os valores informados pelos estados são, no somatório entre 2000-2006, 50 e 37\% superiores, respectivamente. Isso pode sinalizar desde erros técnicos dos estados no preenchimento dos demonstrativos da LRF até indícios da chamada "contabilidade criativa".

As diferenças entre nossas estimativas e as da STN, como já mencionado, estão concentradas no período 2002-2006, quando o plano de contas dos balanços publicados pelos estados passou a abrir os grupos de despesa por elemento, permitindo que identificássemos as inversões de caráter financeiro. Ambas as estimativas, entretanto, são inferiores às do BC, porque, como já salientamos, registram as despesas pela ótica da competência, e não de caixa.

Com base na variação do estoque de restos a pagar, construímos uma variável de ajuste caixa/competência, que está apresentada na tabela 3. Essa variável corresponde, quando positiva, a uma ampliação dos restos a pagar. Considerando que parte dos restos a pagar (RAPs) pode ser cancelada, a 
nossa estimativa corresponde a um valor mínimo que deve ser somado ao SUP_PRI EOE para ser comparado aos números do Banco Central.

Após esse ajuste, entretanto, nossa estimativa de resultado primário pelo critério "acima da linha" mantém-se, no somatório entre 2000 e 2006, $\mathrm{R} \$ 5$ bilhões abaixo dos resultados indicados pelo BC. Uma possível hipótese para a discrepância é que parte dos RAPs tenha sido cancelada e que, portanto, o ajuste caixa/competência necessário seja maior do que o indicado pela simples observação dos estoques em final de período. Contudo, também é possível apontar falhas na metodologia do BC, como o fato de a mesma não considerar os RAPs (até mesmo processados) e outras dívidas de caráter flutuante.

Isso ocorre tanto porque esse tipo de dívida não está registrado no sistema financeiro, como também por certa falta de compreensão da importância que os RAPs assumiram para as finanças públicas. Ou seja, em geral, assume-se que o RAP é uma despesa que, mais cedo ou mais tarde, será paga, e que, no fluxo, seus efeitos serão mínimos. As evidências, entretanto, apontam para um sentido contrário: embora os estados tenham melhorado a situação de caixa, o fizeram principalmente pela ampliação das disponibilidades, visto que o estoque de restos a pagar continua crescendo.

\subsection{As despesas de pessoal nos estados}

Nosso próximo passo é analisar a evolução das despesas de pessoal de forma mais detalhada, abrindo os dados por estado. Como vimos na primeira parte deste artigo, as despesas de pessoal apresentaram um pequeno crescimento como proporção da RCL, embora estejam estabilizadas como proporção do PIB. Considerando a variação real, acima do deflator do PIB, entretanto, o aumento acumulado entre 2000 e 2006 chega a 26,3\% no critério bruto ou $27,0 \%$ no critério líquido, de acordo com as regras da LRF.

Essas evidências mostram que as pressões fiscais decorrentes das despesas de pessoal não estão totalmente controladas, como sugerem algumas estatísticas apresentadas pelos governos estaduais. Os demonstrativos de gasto com pessoal previstos pela LRF, referentes aos Executivos estaduais, são reproduzidos na página da STN na Internet e indicam que, entre 2000 2006, a despesa líquida no conjunto das unidades da federação caiu de $47,85 \%$ da RCL para 40,80\%. Nossas estimativas, entretanto, mesmo após um ajuste para deduzir as contribuições previdenciárias dos servidores, 
mostram que o recuo da despesa líquida das administrações direta e indireta dos estados, incluindo todos os poderes, foi de $54,37 \%$ para $53,62 \%$ da RCL, como pode ser visto em detalhes na tabela 4 . Essa tabela apresenta em uma coluna os porcentuais atribuídos aos Executivos e em outra a estimativa para o conjunto dos poderes.

A diferença entre as colunas Total e Executivo indica, a princípio, o montante de recursos que está sendo canalizado para cobrir as despesas dos demais poderes ou que está deixando de entrar no cômputo do Executivo por critérios contábeis diferentes daqueles que constam nos manuais da STN, como é o caso das unidades da federação em que as despesas dos pensionistas e aposentados — ou do imposto de renda retido na fonte dos servidores — são deduzidas do cálculo. Essa diferença aumenta de 6,51\% para 12,82\% da RCL entre 2000 e 2006.

A tabela 4 revela, entretanto, diferenças negativas entre as duas colunas no ano 2000, o que indica algum erro ou divergência de apuração, provocado talvez pelo fato de os dados apresentados no balanço orçamentário, utilizado em nossas estimativas, omitir as despesas dos demais poderes. De qualquer forma, essas divergências estão restritas a pequenos estados, exceto no caso da Bahia e Pernambuco.

Retirando esses estados do demonstrativo, entretanto, as comparações não mudam qualitativamente: as despesas de pessoal, em média, passam a registrar aumento de 53,07\% para 54,51\% da RCL no período, e a diferença atribuída aos demais poderes cresce de 7,65\% para 12,64\% da RCL. Como o limite máximo de despesa com pessoal é de $49 \%$ da RCL no Executivo e de $11 \%$ no somatório dos demais poderes, os dados indicam forte evidência de que órgãos nos estados que estão descumprindo as regras da LRF. Isso fica mais claro nos casos em que a diferença apurada é bem superior aos $11 \% \mathrm{da}$ RCL, como Alagoas, Ceará, Mato Grosso do Sul, Paraíba, Paraná, Rio de Janeiro, Rondônia, Rio Grande do Sul e Sergipe.

Alguns desses casos já são de conhecimento público, porque levaram alguns Executivos a sofrer consequências do descumprimento dos limites por outros poderes, mas a maioria tem se mantido obscurecida pela contabilidade criativa, inspirada em interpretações dos Tribunais de Contas dos estados. Essas evidências reforçam a necessidade de o governo federal e o Con- 
gresso se empenharem na regulamentação do Conselho de Gestão Fiscal, órgão incumbido pela LRF de promover a "harmonização e coordenação entre os entes da federação" e a "adoção de normas de consolidação das contas públicas, padronização das prestações de contas e dos relatórios e demonstrativos da gestão fiscal", sob pena de o ajuste fiscal recair exclusivamente sobre os servidores do Executivo.

Tabela 4: Discrepâncias na estimativa da despesa líquida de pessoal

\begin{tabular}{|c|c|c|c|c|c|c|}
\hline \multirow{3}{*}{ UF } & & & & & & $\% \mathrm{RCL}$ \\
\hline & \multicolumn{3}{|c|}{2000} & \multicolumn{3}{|c|}{2006} \\
\hline & Executivo & Total & Diferença & Executivo & Total & Diferença \\
\hline$A C$ & 47,32 & 58,24 & 10,92 & 48,11 & 56,32 & 8,21 \\
\hline $\mathrm{AL}$ & 44,29 & 55,38 & 11,10 & 45,00 & 59,04 & 14,04 \\
\hline AM & 44,76 & 37,28 & $(7,49)$ & 41,07 & 44,01 & 2,95 \\
\hline AP & 36,86 & 34,16 & $(2,69)$ & 41,70 & 50,25 & 8,55 \\
\hline BA & 35,89 & 31,90 & $(3,98)$ & 42,33 & 53,37 & 11,04 \\
\hline CE & 42,59 & 43,91 & 1,32 & 38,43 & 55,45 & 17,02 \\
\hline DF & 32,89 & 38,20 & 5,31 & 41,19 & 47,91 & 6,71 \\
\hline ES & 44,90 & 50,20 & 5,29 & 32,02 & 46,73 & 14,71 \\
\hline GO & 49,17 & 54,86 & 5,68 & 42,96 & 59,51 & 16,55 \\
\hline MA & 48,54 & 42,92 & $(5,61)$ & 35,58 & 45,91 & 10,34 \\
\hline MG & 63,86 & 66,83 & 2,96 & 44,58 & 54,22 & 9,64 \\
\hline MS & 45,68 & 55,55 & 9,87 & 43,55 & 58,73 & 15,18 \\
\hline MT & 42,66 & 52,31 & 9,65 & 40,72 & 51,17 & 10,45 \\
\hline PA & 42,26 & 60,51 & 18,24 & 44,09 & 54,07 & 9,99 \\
\hline PB & 42,10 & 33,43 & $(8,66)$ & 45,61 & 64,86 & 19,25 \\
\hline PE & 49,22 & 42,08 & $(7,14)$ & 42,16 & 52,44 & 10,27 \\
\hline $\mathrm{PI}$ & 45,22 & 45,33 & 0,10 & 43,60 & 51,88 & 8,28 \\
\hline PR & 45,58 & 50,11 & 4,53 & 44,91 & 59,12 & 14,21 \\
\hline RJ & 39,90 & 63,71 & 23,81 & 27,49 & 49,80 & 22,31 \\
\hline RN & 41,15 & 47,21 & 6,06 & 48,23 & 60,72 & 12,49 \\
\hline RO & 45,03 & 54,83 & 9,81 & 39,84 & 53,96 & 14,12 \\
\hline RR & 38,68 & 37,02 & $(1,66)$ & 28,74 & 36,91 & 8,17 \\
\hline RS & 61,68 & 63,44 & 1,77 & 41,30 & 62,67 & 21,37 \\
\hline SC & 52,03 & 50,89 & $(1,14)$ & 43,99 & 54,71 & 10,72 \\
\hline SE & 57,88 & 45,79 & $(12,09)$ & 42,88 & 57,50 & 14,61 \\
\hline SP & 49,27 & 56,82 & 7,55 & 42,84 & 52,98 & 10,14 \\
\hline TO & 34,15 & 37,82 & 3,66 & 44,70 & 46,84 & 2,14 \\
\hline Total & 47,85 & 54,37 & 6,51 & 40,80 & 53,62 & 12,82 \\
\hline
\end{tabular}

Fonte: Executivo (valor publicado pela STN) e Total (estimativa própria) 
Tabela 5: Estados. evolução de despesas selecionadas em valor real (deflator PIB)

\begin{tabular}{lccrrrrrr}
\hline Ano & 2000 & 2001 & 2002 & 2003 & 2004 & 2005 & 2006 & Var. 2002-2006 \\
\hline ODC_TOT & 47.440 & 56.421 & 49.280 & 53.070 & 59.101 & 59.492 & 63.601 & $29,1 \%$ \\
\hline ODC_MAQ & - & - & 8.542 & 9.231 & 10.118 & 10.554 & 11.203 & $31,2 \%$ \\
\hline ODC_AUX & - & - & 3.693 & 3.518 & 3.488 & 3.679 & 4.646 & $25,8 \%$ \\
\hline ODC_TER & - & - & 27.181 & 24.781 & 27.887 & 30.661 & 29.786 & $9,6 \%$ \\
\hline PES_DED & - & - & 2.943 & 1.994 & 2.721 & 2.818 & 2.448 & $-16,8 \%$ \\
\hline INV & 17.096 & 19.222 & 19.369 & 14.049 & 15.681 & 19.125 & 22.005 & $13,6 \%$ \\
\hline RCL & 190.704 & 204.910 & 206.967 & 201.759 & 216.094 & 229.016 & 242.154 & $17,0 \%$ \\
\hline
\end{tabular}

Fonte: Elaboração própria (a partir dos balanços orçamentários - EOE).

\subsection{Outras despesas correntes e investimentos}

Por último, dedicamos esta seção sobre a situação fiscal dos estados a analisar brevemente a evolução das despesas de custeio em comparação com os investimentos e os gastos de pessoal. Se os gastos de pessoal indicam uma relativa estabilidade, o mesmo não pode ser dito do grupo Outras Despesas Correntes, que no agregado dos estados cresceu $29,1 \%$ em termos reais desde 2002, enquanto as de pessoal avançaram no mesmo período $9,5 \%$, que compara dois finais de mandato.

Se abrirmos essas despesas por elemento, vamos verificar que algumas delas cresceram até mais do que os porcentuais mencionados. É o caso do grupo aqui denominado ODC_MAQ, que reúne os gastos de custeio da máquina, como diárias de viagem, passagens e material de consumo. Como pode ser visto na tabela 5, eles cresceram 31,2\% acima do deflator do PIB entre $2002 \mathrm{e}$ 2006. A escolha desse período para a análise deve-se à impossibilidade de obter os gastos com esse tipo de desagregação para anos anteriores.

Pouco abaixo aparecem os gastos do grupo identificado como ODC_ AUX, que reúne despesas com diversos tipos de auxílios e benefícios que cresceram 25,8\% em termos reais entre 2002 e 2006. Esse subgrupo das despesas de custeio reúne gastos que também beneficiam os servidores públicos, como auxílio-alimentação e transporte, auxílio-creche e funeral, além de auxílio a pesquisadores, estudantes e benefícios previdenciários e assistenciais em geral. Por uma decisão da STN, tomada logo após a entrada em vigor da LRF, foi regulamentado que tais despesas - de caráter in- 
denizatório — seriam contabilizadas em ODC, e não mais Pessoal e Encargos Sociais.

Independentemente das razões para essa tomada de decisão, o fato é que ela abriu uma importante lacuna por meio da qual os governos podem ampliar os benefícios dos seus servidores sem impacto nos parâmetros da LRF. O mesmo ocorre, por exemplo, com as despesas que entram na rubrica Pessoal, mas são descontadas no cálculo da despesa líquida, como as sentenças judiciais e de exercícios anteriores. Cria-se, naturalmente, uma lacuna que pode ser usada pelo administrador para fugir dos limites da lei.

Essas despesas, identificadas como PES_DED na tabela 5, apresentam variação negativa entre 2002 e 2006, mas, na verdade, vêm crescendo desde 2003. Algo parecido ocorre com o grupo de despesas identificadas como ODC_TER, que reúne os elementos associados à contratação de serviços de terceiros. Depois de cair entre 2002 e 2003, essas despesas vêm crescendo ininterruptamente e são, atualmente, a principal válvula de escape utilizada por muitos governos para driblar as restrições sobre as despesas de pessoal.

Ao estipular um controle apenas sobre os gastos com salário dos servidores públicos, a LRF cria um estímulo para que as administrações públicas aprofundem as contratações de serviços de terceiros, sem qualquer comprovação de que sejam mais econômicas para os cofres públicos.

Por outro lado, os dados mostram que os investimentos cresceram 13,6\% entre 2002 e 2006, depois de uma queda acentuada no início do último mandato. A principal característica da evolução dos investimentos, pelos dados que podemos observar entre 2000 e 2006, tem sido a de oscilar de acordo com o ciclo eleitoral. Ou seja, eles sempre caem em valor no primeiro ano de mandato e depois começam a crescer gradualmente, atingindo o pico no último ano de mandato, quando o governador tem mais necessidade de mostrar serviço e realizações à população do seu estado.

\section{CONCLUSÕES}

Este artigo oferece um panorama da evolução das finanças públicas estaduais entre 1998 e 2006 a partir de uma gama variada de indicadores derivados dos balanços orçamentários e patrimoniais dos entes subnacionais. A matriz de 
indicadores resultante do trabalho de depuração e comparação dos dados mostra que a situação fiscal dos estados evoluiu positivamente desde a introdução da Lei de Responsabilidade Fiscal e que o aumento da receita tem propiciado um novo padrão de financiamento das despesas, sem endividamento e com mais controle dos restos a pagar. Constatamos, entretanto, que há uma discrepância não explicada entre os resultados primários calculados a partir dos dados contábeis de estados e aqueles apurados pelo Banco Central, assim como indícios de "contabilidade criativa" na apresentação dos demonstrativos de gasto com pessoal dos estados.

Os resultados obtidos também indicam que, em que pesem os controles sobre as despesas de pessoal (em muitos casos restritos aos Executivos), os estados têm expandido ininterruptamente os outros gastos correntes. A expansão dos gastos correntes não só supera os investimentos, na comparação entre 2002 e 2006, como neste último caso há uma tendência de redução deles nos dois primeiros anos de mandato e seu posterior aumento, seguindo uma estratégia eleitoral. Ou seja, visivelmente os investimentos têm sido sacrificados como subproduto do tipo de ajuste fiscal colocado em prática nos estados, embora no período mais recente haja uma tendência geral (com exceções, como no caso do Rio Grande do Sul) de recuperação propiciada pelo bom desempenho das receitas estaduais.

A nossa premissa básica é de que o ajuste fiscal necessário ao equilíbrio macroeconômico, para que seja sustentável a longo prazo, não pode deixar de observar certos níveis mínimos de qualidade na alocação de recursos e na prestação dos serviços públicos. A eliminação de deficit pelo caminho da redução dos investimentos ou da baixa qualidade na prestação de serviços públicos na área social pode dar resultados a curto prazo, mas não cria as bases para a solução estrutural dos desequilíbrios fiscais e enfraquece as economias regionais.

Repensar o ajuste fiscal no país exige, em primeiro lugar, reconhecer que os investimentos não são um gasto como qualquer outro, por sua propriedade de criar capacidade produtiva e riqueza, tanto para o estado quanto para a economia do setor privado. Dessa forma, é preciso que se criem meios para que os estados mais endividados e em maior dificuldade financeira recuperem sua capacidade de investimento. 


\section{ANEXOS}

Anexo 1: Glossário do Plano de Contas da EOE (1998-2001)

\begin{tabular}{|c|c|}
\hline & Receitas \\
\hline $\begin{array}{l}\text { Receita Primária } \\
\text { (REC_PRI) }\end{array}$ & $\begin{array}{l}\text { + Receita } \\
\text { - Receitas Financeiras } \\
\text { - Receita de Operações de Crédito } \\
\text { - Receita de Alienação de Bens }\end{array}$ \\
\hline $\begin{array}{l}\text { Receita Tributária } \\
\text { (REC_TRI) }\end{array}$ & $\begin{array}{l}\text { + Receita de ISS } \\
\text { + Receita de IRRF } \\
\text { + Outros (IPTU, ITBI, Taxas e Melhoria) }\end{array}$ \\
\hline $\begin{array}{l}\text { Outras Receitas Próprias } \\
\text { (OUT_PRO) }\end{array}$ & $\begin{array}{l}\text { + Receita de Contribuições } \\
\text { + Receita Patrimonial } \\
\text { - Receitas Financeiras } \\
\text { + Receita Agropecuária } \\
\text { + Receita Industrial } \\
\text { + Receita de Serviços }\end{array}$ \\
\hline $\begin{array}{l}\text { Receitas Próprias } \\
\text { (REC_PRO) }\end{array}$ & $=\left(R_{E} C_{-} T R I\right)+\left(O U T \_P R O\right)$ \\
\hline $\begin{array}{l}\text { Transf. de Capital } \\
\text { (TRA_CAP) }\end{array}$ & $\begin{array}{l}\text { + Receitas de Capital } \\
\text { - Receita de Operações de Crédito } \\
\text { - Receita de Alienação de Bens }\end{array}$ \\
\hline $\begin{array}{l}\text { Transf. Correntes } \\
\text { (TRA_COR) }\end{array}$ & $=($ REC_PRI) $-($ REC_PRO) $-($ TRA_CAP $)$ \\
\hline $\begin{array}{l}\text { Receita Corrente Líquida } \\
\text { (RCL) }\end{array}$ & + Receita Corrente \\
\hline & Despesas \\
\hline $\begin{array}{l}\text { Despesa Financeira } \\
\text { (DFI) }\end{array}$ & $\begin{array}{l}\text { + Juros e Encargos da Dívida } \\
\text { + Inversões Financeiras } \\
\text { + Amortização de Dívida }\end{array}$ \\
\hline $\begin{array}{l}\text { Despesa Primária } \\
\text { (DES_PRI) }\end{array}$ & $\begin{array}{l}+ \text { Despesa Total } \\
-(\text { DFI) }\end{array}$ \\
\hline $\begin{array}{l}\text { Pessoal Bruto } \\
\text { (PES_TOT) }\end{array}$ & $\begin{array}{l}\text { + Despesas de Pessoal } \\
+ \text { Inativos } \\
+ \text { Pensionistas } \\
+ \text { Salário-família }\end{array}$ \\
\hline $\begin{array}{l}\text { Pessoal Deduções } \\
\text { (PES_DED) }\end{array}$ & $\begin{array}{l}\text { Indisponível: para efeito de comparação, tomou-se a média das } \\
\text { deduções de } 2002 \text { em relação ao total da despesa de pessoal. }\end{array}$ \\
\hline
\end{tabular}


(Continuação do Anexo1)

\begin{tabular}{|c|c|}
\hline Despesa de Custeio & + Serviços de Terceiros/Encargos \\
\hline (ODC_TOT) & + Outros Custeios \\
\hline & + Outras Transf. Pessoas \\
\hline & + Contribuição Pasep \\
\hline & + Demais Transferências Correntes \\
\hline & + Outras Despesas Correntes \\
\hline Custeio Máquina & + Outros Custeios \\
\hline (ODC_MAQ) & \\
\hline Custeio Auxílios & + Outras Transf. Pessoas \\
\hline (ODC_AUX) & \\
\hline Custeio Terceiros & + Serviços de Terceiros/Encargos \\
\hline (ODC_TER) & \\
\hline Investimento (INV) & + Investimentos \\
\hline & Ativo e Passivo \\
\hline Dívida Consolidada & + OPC Internas em Circulação \\
\hline (DC_TOT) & + OPC Externas em Circulação \\
\hline & + Outros débitos à Pagar \\
\hline & + OPC Internas de Longo Prazo \\
\hline & + OPC Externas de Longo Prazo \\
\hline & + Obrigações Legais e Tributárias \\
\hline & + Obrigações a Pagar LP \\
\hline Deduções & - RAPs Processados \\
\hline (DC_DED) & + Ativo Financeiro Disponível \\
\hline & + Créditos em Circulação \\
\hline & + Empréstimos e Financiamentos CP \\
\hline & + Outros Créditos em Circulação CP \\
\hline & - Provisão Devedores Duvidosos CP \\
\hline Dívida Líquida (DCL) & $=\left(D C_{-} \mathrm{TOT}\right)-(\mathrm{DC}-\mathrm{DED})$ \\
\hline Disponibilidade financeira & + Ativo Financeiro Disponível \\
\hline (ATI_DIS) & + Créditos em Circulação \\
\hline Obrigações financeiras & - Depósitos Passivo Financeiro \\
\hline (PAS_OBR) & - RAP Processados \\
\hline & - RAP Não Processados \\
\hline & - Credores Diversos \\
\hline Suficiência (SUF_CXA) & $=($ ATI_DIS $)-($ PAS_OBR $)$ \\
\hline
\end{tabular}

\section{Gasto por Função}

\begin{tabular}{ll}
\hline Gasto Legislativo (LEG) & + Despesa na Função Legislativa \\
\hline Gasto Social (SOC) & + Função Educação/Cultura \\
& + Função Saúde/Saneamento \\
\hline Gasto em & + Função Transporte \\
Infraestrutura (INF) & + Função Habitação/Urbanismo \\
& + Função Energia/Recursos Minerais \\
\hline
\end{tabular}


Anexo 2: Glossário do Plano de Contas da EOE (2002-2006)

\begin{tabular}{|c|c|}
\hline & Receitas \\
\hline Receita Primária & + Receita Orçamentária \\
\hline (REC_PRI) & - Receita de Valores Mobiliários \\
\hline & - Receita de Operações de Crédito \\
\hline & - Receita de Alienação de Bens \\
\hline & - Receita de Amortização Empréstimos \\
\hline Receita Tributária & + Receita de ISS \\
\hline (REC_TRI) & + Receita de IRRF \\
\hline & + Outros (IPTU, ITBI, Taxas e Melhoria) \\
\hline Outras Receitas Próprias & + Receita de Contribuiç̧̃es \\
\hline (OUT_PRO) & + Receita Patrimonial \\
\hline & - Receita de Valores Mobiliários \\
\hline & + Receita Agropecuária \\
\hline & + Receita Industrial \\
\hline & + Receita de Serviços \\
\hline Transf. de Capital & + Receitas de Capital \\
\hline (TRA_CAP) & - Receita de Operações de Crédito \\
\hline & - Receita de Alienação de Bens \\
\hline & - Receita de Amortização Empréstimos \\
\hline Transf. Correntes & $=($ REC_PRI $)-($ REC_PRO $)-\left(T R A \_C A P\right)$ \\
\hline (TRA_COR) & \\
\hline Receita Corrente Líquida & + Receita Corrente \\
\hline$(\mathrm{RCL})$ & - Deduções da Receita Corrente \\
\hline
\end{tabular}

\section{Despesas}

\begin{tabular}{ll}
\hline Despesa Financeira & + Juros e Encargos da Dívida \\
(DFI) & + IF/Aquis. Títulos Capital Integral \\
& + IF/Concessão de Empréstimos \\
& + Amortização de Dívida \\
\hline Despesa Primária & + Despesa Total \\
(DES_PRI) & - (DFI) \\
\hline Pessoal Bruto & + PES/Total \\
(PES_TOT) & + ODC/Aposentadorias e Reformas \\
& + ODC/Pensões \\
\hline Pessoal Deduções & - Pesad/Sentenças Judiciais \\
(PES_DED) & - Pesad/Desp. de Ex. Anteriores \\
& - Pesad/Indenizações e Restituições \\
\hline Pessoal Ativo & + Pesad/Venc. e Vant. Fixas/Civil \\
(PES_ATI) & + Pesad/Venc. e Vant. Fixas/Militar \\
& + Pesad/Outras Desp. Variáveis/Civil \\
& + Pesad/Outras Desp. Variáveis/Militar
\end{tabular}


(Continuação do Anexo 2)

\begin{tabular}{ll}
\hline Despesa de Custeio & + ODC Total \\
(ODC_TOT) & - ODC/Aposentadorias e Reformas \\
\hline Custeio Máquina & + ODC/Pensões \\
(ODC_MAQ) & + ODC/Diárias Civil \\
& + ODC/Maárias Militar \\
& + ODC/Material de Consumo de Distribuição Gratuita \\
& + ODC/Passagens e Locomoção \\
\hline Custeio Auxílios & + ODC/Outros Benefícios Previdenciários \\
& + ODC/Outros Benefícios Assistenciais \\
& + ODC/Salário-família \\
& + ODC/Auxílio Financeiro a Estudantes \\
& + ODC/Auxílio Financeiro a Pesq. \\
& + ODC/Auxílio-alimentação \\
& + ODC/Auxílio-transporte \\
\hline Investimento (INV) & + ODC/Contratação Temporária \\
& + ODC/Serviços de Consultoria \\
& + ODC/Outros Serviços Pessoa Física \\
& + ODC/Locação de Mão de Obra \\
& + ODC/Outros Serviços Pessoa Jurídica \\
& + Investimentos \\
\hline Custeio Terceiros (ODC_TER) &
\end{tabular}

\section{Ativo e Passivo}

\begin{tabular}{ll}
\hline Dívida Consolidada & + OPC Internas em Circulação \\
(DC_TOT) & + OPC Externas em Circulação \\
& + Precatórios Passivo NF \\
& + OPC Internas de Longo Prazo \\
& + OPC Externas de Longo Prazo \\
& + Obrigações Legais e Tributárias \\
& + Obrigações a Pagar LP \\
\hline Deduções & - RAP Processados \\
(DC_DED) & + Ativo Financeiro Disponível \\
& + Créditos em Circulação \\
& + Empréstimos e Financiamentos CP \\
& + Outros Créditos em Circulação CP \\
& - Provisão Devedores Duvidosos CP \\
\hline Dívida Líquida (DCL) & $=$ (DC_TOT) - (DC_DED) \\
\hline Disponibilidade Financeira & + Ativo Financeiro Disponível \\
(ATI_DIS) & + Créditos em Circulação \\
\hline
\end{tabular}


(Continuação do Anexo 2)

\begin{tabular}{ll}
\hline Obrigações financeiras & - Depósitos Passivo Financeiro \\
(PAS_OBR) & - RAP Processados \\
& - RAP Não Processados \\
& - Credores Diversos \\
& - Adiantamentos Recebidos \\
& - Outras Obrigações a Pagar \\
& $=$ (ATI_DIS) - (PAS_OBR) \\
\hline Suficiência (SUF_CXA) & \\
\hline & Gasto por Função \\
\hline Gasto Legislativo & + Despesa na Função Legislativo \\
(LEG) & + Despesa na Função Educação \\
\hline Gasto Social & + Despesa na Função Cultura \\
(SOC) & + Despesa na Função Saúde \\
& + Despesa na Função Sanemamento \\
\hline Infraestrutura (INF) & + Função Transporte \\
& + Função Habitação \\
& + Função Urbanismo \\
& + Função Energia \\
\hline Gasto em &
\end{tabular}

\section{NOTAS}

1. O Estado de S. Paulo: "Brecha na lei permite gastos com funcionalismo acima do limite" (17/4/2006, A4); "Assembléias resistem à Lei Fiscal (15/5/2006, A7); "Governos de oito Estados ficam na mira da Lei Fiscal” (22/2/2007, A4).

2. Pós-keynesianos, como Davidson (1991), sugerem que os deficits surgem da necessidade de intervenção do estado sobre a economia em momentos de maior incerteza no ambiente econômico, em que os empresários retraem seus investimentos e manifestam "preferência pela liquidez". As incertezas acentuaram-se com a desregulamentação do sistema financeiro e o processo de liberalização, nos anos 1980 e 1990, como fica evidenciado pela maior volatilidade dos preços-chave da economia, o que explicaria por que os governos não conseguem reduzir seus gastos, mesmo em momentos de "paz".

3. A LC no 101/2000 começa logo em seu art. $1^{\circ}, \S 1^{\circ}$, estabelecendo que "a responsabilidade na gestão fiscal pressupõe a ação planejada e transparente, em que se previnem riscos e corrigem desvios capazes de afetar o equilíbrio das contas públicas, mediante o cumprimento de metas de resultados entre receitas e despesas e a obediência a limites e condições...” (Presidência da República, 2000).

4. A redação do art. 42, além de não explicitar uma forma de aferição da regra, dá margem para interpretações de que a restrição sobre restos a pagar só existiria nos últimos oito meses de mandato, não impedindo, por exemplo, que eles se avolumem no período anterior. 
5. A LRF enumera arts. 52, 53, 54 e 55 os demonstrativos que devem compor os relatórios, mas as orientações sobre preenchimento estão detalhadas nos manuais da STN.

6. Os valores de insuficiência de caixa reproduzidos neste trabalho não necessariamente equivalem àqueles informados pelos entes governamentais nos seus relatórios oficiais, já que este trabalho adotou uma metodologia padronizada para todos os estados com base nas orientações da STN, que nem sempre são seguidas pelas áreas contábeis das Secretarias de Fazenda e Finanças.

\section{REFERÊNCIAS BIBLIOGRÁFICAS}

ALESINA, A.; BAYOUMI, T. The Costs and benefits of fiscal rules: evidence from U.S. States. NBER Working Paper, n. 5.614, 1996.

PEROTTI, R. Budget deficits and budget institutions. NBER Working Paper, n. 5.556, 1996.

; PEROTTI, R. The political economy of budget deficits. NBER Working Paper, n. $4.637,1994$.

; TABELLINI, G. A positive theory of budget deficits and government debt. Review of Economic Studies, n. 57, p. 403-414, 1990.

BARRO, R. On the determination of the public debt. Journal of Political Economy, n. 87, p. 940-947, 1979.

BUCHANAN, J.; WAGNER, R. Democracy in Deficit: the political legacy of lord keynes. USA: Academic Press, Inc, 1977.

CUKIERMAN, A.; MELTZER, A. A political theory of government debt and deficits in a neoricardian framework. American Economic Review, n. 79, p. 713-733, 1989.

DADIDSON, P. The neoclassical vs. post keynesian view of government. In: Controversies in Post Keynesian Economics, cap. 7. Aldershot, UK - Edward Elgar, 1991.

FIORAVANTE, D. G.; PINHEIRO, M. M. S.; VIEIRA, R. S. Lei de responsabilidade fiscal e finanças públicas municipais: impactos sobre despesas com pessoal e endividamento. Texto para Discussão, Brasília: IPEA, n. 1.223, 2006.

GIUBERTI, A. C. Lei de responsabilidade fiscal: efeitos sobre o gasto com pessoal dos municípios brasileiros. Finanças públicas: X Prêmio Tesouro Nacional - 2005. Coletânea de Monografias. Brasília: Secretaria do Tesouro Nacional, 2006, p. 803-841.

INMAN, R. Do balanced budget rules work? U.S. Experience and possible lessons for the EMU. NBER Working Paper, n. 5.838, 1996.

LUCAS, R.; STOKEY, N. Optimal fiscal and monetary policy in an economy without Capital. Journal of Monetary Economics, n. 12, p. 55-94, 1983.

MENEZES, R. T. Impactos da lei de responsabilidade fiscal sobre os componentes de despesa dos municípios brasileiros. Finanças públicas: X Prêmio Tesouro Nacional - 2005. Coletânea de Monografias. Brasília: Secretaria do Tesouro Nacional, 2006, p. 747-801.

MILESI-FERRETTI, G. M. Good, bad or ugly? On the effects of fiscal rules with creative accounting. IMF Working Paper WP/00/172, 2000. 
POTERBA, J. M. Do budget rules work? NBER Working Paper, n. 5.550, 1996.

ROGOFF, K. Equilibrium political budget cycles. American Economic Review, n. 80, p. 21-26, 1990.

SECRETARIA DO TESOURO NACIONAL (STN). Execução Orçamentária dos Estados. Disponível em: http://www.stn.fazenda.gov.br/estados_municipios. Documentos Relacionados, 1995-2006.

Manual de Elaboração do Anexo de Riscos Fiscais e Relatório de Gestão Fiscal. 7. ed. Disponível em: http://www.stn.fazenda.gov.br//hp/lei_responsabilidade_fiscal.asp, 2007.

SOUZA, S. S. Ambiente institucional e resultados fiscais: os diferentes impactos da lei de responsabilidade fiscal. Finanças Públicas: X Prêmio Tesouro Nacional - 2006. Coletânea de Monografias. Brasília: Secretaria do Tesouro Nacional, 2007, p. 833-886.

VON HAGEN, J.; HARDEN, I. J. Budget Process and commitment to fiscal discipline. European Economic Review, Amsterdam, n. 39, p. 771-779, 1995.

WOOLDRIDGE, J. Econometrics Analysis of Cross Section and Panel Data. London, England: The MIT Press, 2002. 